\title{
Novel horizontal transmission route for Enteromyxum leei (Myxozoa) by anal intubation of gilthead sea bream Sparus aurata
}

\author{
Itziar Estensoro, $\mathbf{M}^{\mathrm{a}}$ José Redondo, Pilar Alvarez-Pellitero, \\ Ariadna Sitjà-Bobadilla*
}

Instituto de Acuicultura de Torre de la Sal, Consejo Superior de Investigaciones Científicas, Torre de la Sal s/n, 12595 Ribera de Cabanes, Castellón, Spain

\begin{abstract}
The aim of the present study was to determine whether Enteromyxum leei, one of the most threatening parasitic diseases in Mediterranean fish culture, could be transmitted by peranal intubation in gilthead sea bream Sparus aurata L. Fish were inoculated either orally or anally with intestinal scrapings of infected fish in 3 trials. Oral transmission failed, but the parasite was efficiently and quickly transmitted peranally. Prevalence of infection was $100 \%$ at $60 \mathrm{~d}$ post inoculation (p.i.) in

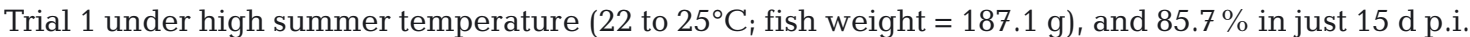
in Trial 3 using smaller fish $(127.5 \mathrm{~g})$ at autumn temperature $\left(19\right.$ to $\left.22^{\circ} \mathrm{C}\right)$. In Trial 2 , prevalence reached $60 \%$ at $60 \mathrm{~d}$ p.i. in the group reared at constant temperature $\left(18^{\circ} \mathrm{C}\right)$, whereas no fish was infected in the group that was kept at low winter temperature $\left(11\right.$ to $\left.12^{\circ} \mathrm{C}\right)$, although infection appeared $(46.1 \%$ at $216 \mathrm{~d}$ p.i.) when temperature increased in spring. The arrested development at low temperature has important epidemiological consequences, as fish giving false negative results in winter can act as reservoirs of the parasite. Histopathological examination showed a posterior-anterior intestinal gradient in the progression of the infection, in terms of both intensity and parasite maturation. Thus, peranal intubation provides a very uniform, reliable and faster mode of transmission of $E$. leei than the commonly used transmission methods (cohabitation, exposure to infected effluent and oral inoculation), which require long exposure times or give variable and unpredictable results.
\end{abstract}

KEY WORDS: Myxosporea · Experimental transmission · Teleostei · Aquaculture · Temperature · Histopathology

Resale or republication not permitted without written consent of the publisher

\section{INTRODUCTION}

Since the first description of Enteromyxum leei as Myxidium leei in cultured gilthead sea bream Sparus aurata from southern Cyprus (Diamant et al. 1994), the parasite has been reported along the entire Mediterranean basin, the Red Sea and Japan, to date having been recorded in $>46$ fish species (Diamant 1995, 1998, Le Breton \& Marques 1995, Sakiti et al. 1996, Paperna 1998, Zrnčić et al. 1998, Padrós et al. 2001, Marino et al. 2004, Yanagida et al. 2004, 2006, Yasuda et al. 2005, Diamant et al. 2006, Sitjà-Bobadilla et al. 2007). This myxosporean produces severe enteritis and is one of the most threatening parasites in Mediterranean fish culture. It causes anorexia, anaemia, emaciation, cachexia and death, which can even lead to the abandonment of some farms in specific culture locations (Palenzuela 2006, Rigos \& Katharios 2010). Despite its economic impact, relatively little is known about its transmission and infection routes, and the primary host species in the wild remains unknown.

Thus far, Enteromyxum leei has been experimentally transmitted to various fish species via effluent, cohabitation and oral routes (Diamant 1997, 1998, Diamant \& Wajsbrot 1997, Yasuda et al. 2002, 2005, Muñoz et al. 2007, Sitjà-Bobadilla et al. 2007, Alvarez-Pellitero et al. 2008). All these trials depend on a source of infected fish, since in vitro culture of this parasite, as any 
Myxosporea, has not been achieved. Experimental transmissions by cohabitation and exposure to infected effluent remarkably mimic the natural conditions for the transmission of the disease in cultured fish. However, for gilthead sea bream, it takes $\sim 3$ to 4 mo to achieve high prevalence of infection and to develop disease signs. Furthermore, a precise and uniform infective dose and the initial day of entrance of the parasite cannot be assured for each individual. Although oral infection tries to avoid these drawbacks, the obtained results have been very variable and unpredictable (Diamant \& Wajsbrot 1997, Sitjà-Bobadilla et al. 2007). Field and experimental data seem to indicate that the distal part of the intestine is the first and main target site of the parasite in gilthead sea bream. Therefore, the aim of the present work was to determine the efficacy of the anal route in the transmission of the myxosporean in comparison with the oral route. The progress of the infection through the digestive tract was also studied.

\section{MATERIALS AND METHODS}

Fish and experimental infections. Naïve gilthead sea bream from a commercial fish farm with no previous records of enteromyxosis were used as recipient (R) fish. Upon arrival, fish were checked for the absence of the parasite and acclimated to the experimental conditions for at least $2 \mathrm{wk}$ before the beginning of the experiment. Water of 37.5 salinity was $1 \mu \mathrm{m}$ filtered and UV irradiated. Fish were allocated in 2001 fibreglass tanks and fed daily with a commercial dry pellet diet at $\sim 1 \%$ of body weight. Donor (D) gilthead sea bream were obtained from experimentally infected stocks that were kept at the facilities of the Instituto de Acuicultura de Torre de la Sal.

$\mathrm{R}$ fish were inoculated with $1 \mathrm{ml}$ of Enteromyxum leei infective material. The inoculum consisted of freshly obtained intestinal scrapings of D fish (see Sitjà-Bobadilla et al. 2007). D and R fish were starved for $1 \mathrm{~d}$ prior to inoculation. Three experimental transmission trials were performed. Trial 1 started in summer and $\mathrm{R}$ fish were inoculated either anally (AT-1) or orally (OT-1) with the same inoculum for 2 consecutive days. In Trial 2 (AT-2), 2 R groups were inoculated once only through the anal route. One group was kept at the natural winter temperature (AT-2-L) and another was reared at a temperature $\geq 18^{\circ} \mathrm{C}$ (AT-2-H). Trial 3 started in autumn (AT-3) and R fish with lower weight than in Trials 1 and 2 (to check if this route was feasible with smaller animals) were inoculated once through the anal route and kept at a water temperature $\geq 18^{\circ} \mathrm{C}$. In all trials, a control (CTRL) group with fish that were not exposed to the parasite, but were inoculated with phosphate-buffered saline (PBS), was established. The details of fish and experimental conditions, temperature, samplings and diagnostic procedures are summarised in Table 1. Disease signs and daily mortalities were recorded throughout the experiments. In lethal samplings, fish were euthanized by overexposure to MS-222 (Sigma), whereas in nonlethal (NL) samplings, fish were slightly anaesthetized with clove oil $\left(0.1 \mathrm{ml} \mathrm{l}^{-1}\right)$. In both cases, fish were starved for $1 \mathrm{~d}$ prior to sampling. In Trials 1 and 2, all the inoculated fish were nonlethally diagnosed at each sampling point, and were euthanized at the last sampling. Therefore, the parasitological status of all the fish and the progression of their infection were obtained at each sampling point.

Parasite diagnosis and histopathology. The infection status was determined by histology (HIS) or NLPCR, except in AT-3 at 40 d post inoculation (p.i.), in which half of the 14 examined fish were diagnosed by light microscopic observation of fresh smears of intestinal scrapings (F). For histological examination, pieces of the anterior, middle and posterior intestine were fixed in $10 \%$ buffered formalin, embedded either in Technovit resin (Kulzer, Heraeus) or paraffin, 2 to $3 \mu \mathrm{m}$ sectioned and stained with toluidine blue (TB), haematoxylin \& eosin (H\&E) or periodic acid-Schiff solution (PAS). In AT-1, additional samples of stomach, oesophagus and pyloric caeca with accumulation of ascitic fluid were taken. NL samples were obtained by probing the rectum with a cotton swab and PCR diagnosis was carried out as described by Palenzuela \& Bartholomew (2002) with primers specific for Enteromyxum leei rDNA. This procedure has been validated against a gold standard (histological observation of the whole digestive tract), and resulted in a high sensitivity (0.96) and specificity (1) (O. Palenzuela unpubl. data). NLPCR was also applied to evaluate the parasitic status of donors, and the absence of the parasite in $\mathrm{R}$ fish upon arrival at the experimental facilities. The prevalence of infection at each sampling point was calculated by considering all the positive fish detected by PCR, histological or fresh examination. The intensity of infection was semiquantitatively evaluated only in histological sections according to a scale $(1+$ to $6+)$ with the following ranges: $1+=1-5 ; 2+=6-10 ; 3+=11-25 ; 4+=$ $26-50 ; 5+=51-100 ; 6+>100$. For each intestinal portion, the mean intensity of infection was calculated. Parasite stages were classified as spores, sporoblasts and proliferative stages, the latter corresponding to Stages 1 to 3 described by Alvarez-Pellitero et al. (2008).

Statistics. The possible influence of temperature on the presence of Enteromyxum leei was studied. Fisher's exact test of significance was applied to the $2 \times$ 2 contingency tables generated in AT-2 (for the infec- 
Table 1. Experimental conditions and sampling details of the experimental transmission of Enteromyxum leei to Sparus aurata by oral (OT) and anal (AT). Trials with the same number were performed simultaneously, using fish with the same initial weight (mean $\pm \mathrm{SD}$ ) that were inoculated with the same infective inocula. Infection was diagnosed using histology (HIS), nonlethal (NL) PCR or fresh smears examination (F). Prevalence of infection values were obtained from the diagnosis of the posterior intestine. The provided temperature values are mean \pm SD obtained for the period between each sampling point and the previous date. Trial 2 was performed at high (H) and low (L) water temperature. p.i.: post inoculation

\begin{tabular}{|c|c|c|c|c|c|c|}
\hline $\begin{array}{l}\text { Transmission } \\
\text { trial }\end{array}$ & $\begin{array}{l}\text { Fish weight } \\
(\mathrm{g})\end{array}$ & $\begin{array}{c}\text { Temperature } \\
\left({ }^{\circ} \mathrm{C}\right)\end{array}$ & Days p.i. & Method & $\begin{array}{l}\text { diagnosis } \\
\text { No. of fish } \\
\text { examined }\end{array}$ & $\begin{array}{l}\text { Prevalence of } \\
\text { infection (\%) }\end{array}$ \\
\hline OT-1 & $187.1 \pm 18.3$ & $\begin{array}{l}25.1 \pm 0.7 \\
22.1 \pm 1.2\end{array}$ & $\begin{array}{l}40 \\
60\end{array}$ & $\begin{array}{c}\text { NL-PCR } \\
\text { HIS }\end{array}$ & $\begin{array}{l}15 \\
15\end{array}$ & $\begin{array}{l}0 \\
0\end{array}$ \\
\hline AT-1 & & $\begin{array}{l}25.1 \pm 0.7 \\
22.1 \pm 1.2\end{array}$ & $\begin{array}{l}40 \\
60\end{array}$ & $\begin{array}{c}\text { NL-PCR } \\
\text { HIS }\end{array}$ & $\begin{array}{l}15 \\
15\end{array}$ & $\begin{array}{l}73.3 \\
100\end{array}$ \\
\hline AT-2-H & $280.3 \pm 20.8$ & $\begin{array}{c}18 \pm 0.5 \\
18 \pm 0.5 \\
24.3 \pm 2.0\end{array}$ & $\begin{array}{c}40 \\
60 \\
326\end{array}$ & $\begin{array}{c}\text { NL-PCR } \\
\text { NL-PCR } \\
\text { HIS }\end{array}$ & $\begin{array}{l}15 \\
15 \\
12\end{array}$ & $\begin{array}{c}20 \\
60 \\
0\end{array}$ \\
\hline AT-2-L & & $\begin{array}{l}11.9 \pm 0.4 \\
12.1 \pm 0.2 \\
17.1 \pm 4.5 \\
24.3 \pm 2.0\end{array}$ & $\begin{array}{c}40 \\
60 \\
216 \\
326\end{array}$ & $\begin{array}{c}\text { NL-PCR } \\
\text { NL-PCR } \\
\text { NL-PCR } \\
\text { HIS }\end{array}$ & $\begin{array}{l}15 \\
15 \\
13 \\
13\end{array}$ & $\begin{array}{c}0 \\
0 \\
46.1 \\
0\end{array}$ \\
\hline AT-3 & $127.5 \pm 25.7$ & $\begin{array}{l}22.4 \pm 0.7 \\
19.7 \pm 1.5\end{array}$ & $\begin{array}{l}15 \\
40\end{array}$ & $\begin{array}{c}\text { HIS } \\
\text { HIS+F }\end{array}$ & $\begin{array}{c}7 \\
14\end{array}$ & $\begin{array}{l}85.7 \\
92.9\end{array}$ \\
\hline
\end{tabular}

tion values obtained at 40 and $60 \mathrm{~d}$ p.i.). Statistical analysis was performed using Sigma Stat software (SPSS) at the significance level of $\mathrm{p}<0.05$.

\section{RESULTS}

During the experimental trials, no mortality due to the disease was registered; among the accidental casualties in AT-1 ( $\mathrm{n}=1)$, AT-2-H $(\mathrm{n}=2)$ and AT-2-L $(\mathrm{n}=1)$, only the latter was Enteromyxum leei-positive (195 d p.i.). None of the $\mathrm{R}$ fish in the oral transmission trial or CTRL animals in all the trials was infected by E. leei, whereas prevalence of infection in most peranally inoculated groups in the 3 trials was very high, reaching $100 \%$ at 60 d p.i. in AT-1 and $92.9 \%$ at 40 d p.i. in AT-3. Table 1 summarizes the prevalence of infection in all the trials and samplings. The highest infection values in anal transmission were obtained in AT-1, coinciding with the highest water temperature. In AT2 , in which 2 groups were identically inoculated and kept at different temperatures, prevalence was again higher in the group with higher temperature (AT-2-H). In contrast, AT-2-L fish were not infected until $216 \mathrm{~d}$ p.i, when temperature naturally increased in spring. In the last sampling, almost 1 yr after the inoculation, no AT-2 fish was infected. When comparing the prevalence of infection in the 3 trials at $40 \mathrm{~d}$ p.i., the highest values were achieved in AT-3 (in which smaller R fish were used). Furthermore, in this trial, the infection was established very early after inoculation (15 d). The Fisher's exact test at $40 \mathrm{~d}$ p.i. showed no dependency of prevalence on temperature $(p=0.224)$, whereas a strong dependency was found at $60 \mathrm{~d}$ p.i. $(\mathrm{p}=0.00069)$. Table 2 shows the prevalence and the mean intensity of infection in each intestinal portion

Table 2. Enteromyxum leei. Prevalence and mean intensity of histologically diagnosed infection in different portions of the digestive tract in gilthead sea bream experimentally infected through the anal (AT) route. AI, MI and PI refer to the anterior, middle and posterior intestine. E. leei stages were classified as spores (SP), disporoblasts (DSB) or proliferative stages (P). p.i.: post inoculation

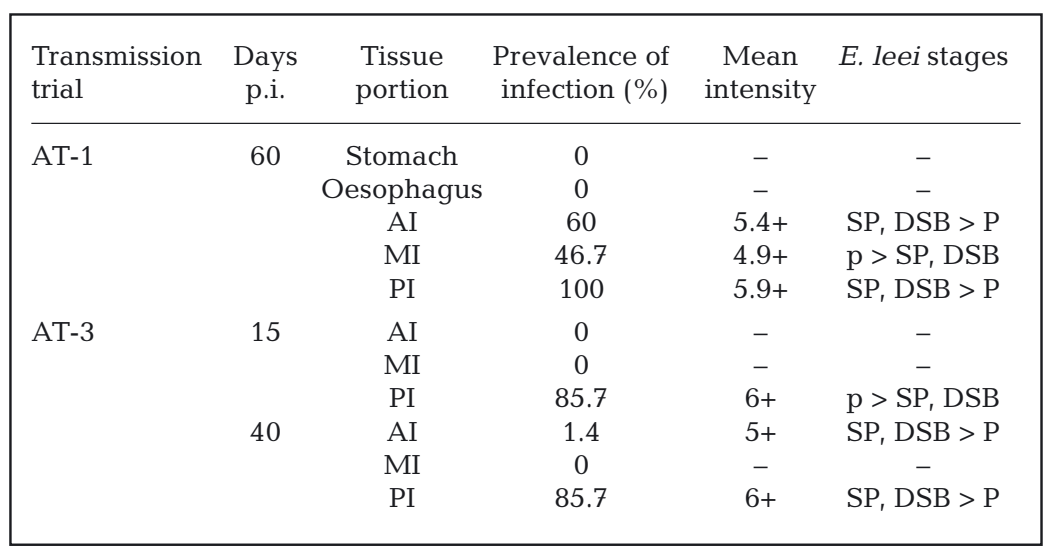


examined histologically in AT-1 and AT-3 at the last sampling. This information was not obtained in AT-2 since fish were not infected in the only sampling point diagnosed by histology. In AT-1, most R animals exhibited accumulation of ascites in the lumen of the intestine, with this accumulation sometimes reaching the pyloric caeca. All R fish had the posterior intestine being massively invaded by the parasite. The anterior intestine and pyloric caeca were also heavily parasitized, and the middle intestine was the least infected portion. All E. leei that showed negative results for the anterior intestine were also negative at the middle portion. No parasites were detected in the stomach or in the oesophagus. In AT-3, the parasite did not spread to the anterior intestine until $40 \mathrm{~d}$ p.i., although intensity of infection was already very high at the posterior part at $15 \mathrm{~d}$ p.i. In both trials, spores and disporous sporoblasts (Fig. 1) were always present in infected posterior and anterior tracts, being frequently detached to the lumen (Fig. 2), whereas they were detected only in $57.1 \%$ of the infected middle intestines of AT-1 fish. Instead, in those portions without sporogonic stages, proliferative stages were abundant (Fig. 3). In infected intestines, the parasite was typically patchily distributed mainly in the anterior and middle portions when intensity of infection was low or medium.

In peranally inoculated fish, the histopathological study revealed the clear damage caused by the parasite in the intestinal tissue of $\mathrm{R}$ fish, regardless of the infected portion. Vacuolation and detachment of the epithelium only appeared in AT-1 fish with high intensity of infection. Inflammatory cells occurred in the lamina propria-submucosa, which was hypertrophied, as well as in the basal part of the epithelium, and consisted of eosinophilic granule cells (EGCs) (Figs. 4 \& 5) and lymphocytes (Fig. 6). EGCs were classified according to their staining pattern as in Alvarez-Pellitero et al. (2008). EGC Type 1 (EGC1) (fuchsia with H\&E, rarely PAS positive and not stained with TB) were abundant in the lamina propria-submucosa (Fig. 4), sometimes also in the epithelium, and were almost in contact with parasite stages. EGC Type 2 (EGC2) (did not stain with H\&E or with $\mathrm{TB}$, with some PAS-positive granules, usually with a polarised pattern) were less abundant and mainly localized in the lamina propria-submucosa (Fig. 5). In $\mathrm{R}$ fish, rodlet cells were very scarce in areas invaded by the parasite, whereas they were abundant in nonparasitized neighbouring areas, even more than in the intestines of CTRL fish (Fig. 7). The number of goblet cells showed a tendency to diminish in infected intestines, and they were occasionally seen close to parasite stages, almost enclosing them (Fig. 8).

In perorally intubated fish, the intestinal epithelium showed empty or vacuolated cells. Other cells contain- ing unidentified debris were compatible with macrophages engulfing cell or parasite debris (Fig. 9). EGCs were abundant in the lamina propria-submucosa, and sometimes infiltrated the epithelium. Lymphocytes were abundant at the base of the epithelium, particularly at the anterior and middle intestines (Fig. 10).

\section{DISCUSSION}

Thus far, anal intubation has been used successfully for vaccine (Crosbie \& Nowak 2004, Vervarcke et al. 2005) or immunomodulator (Swan et al. 2008) delivery in fish. However, peranal parasite transmission has only been reported for the microsporidian Loma salmonae (Shaw et al. 1998) and this is the first report on this type of transmission for a myxosporean. This mode of infection proved to be very effective, achieving high infection levels at $60 \mathrm{~d}$ p.i. (AT-1) or even at 15 d p.i. (AT-3). Since R fish in the AT-2-H and AT-3 trials received the same volume of inoculum, it is tempting to suggest that the higher prevalence of infection achieved after $40 \mathrm{~d}$ in AT-3 was probably due to a higher inoculated parasite infective dose per body weight, as fish were smaller and water temperature was similar. These results are higher than the infection levels commonly obtained via cohabitation or effluent routes for gilthead sea bream (Diamant 1997, Diamant \& Wajsbrot 1997, Sitjà-Bobadilla et al. 2007) and are comparable to those obtained in sharpsnout sea bream Diplodus puntazzo, which is a highly susceptible species (Golomazou et al. 2006, Muñoz et al. 2007). However, in the latter species, $100 \%$ infection prevalence was reached in just $10 \mathrm{~d}$ after cohabitation with infected donors and the entire intestinal tract was invaded at $20 \mathrm{~d}$ post exposure (Alvarez-Pellitero et al. 2008).

The present study shows a clear relationship between prevalence and water temperature in peranal infections. Results confirm those of previous oral infections with Enteromyxum fugu and E. leei in tiger puffer Takifugu rubripes, in which the onset of the disease was suppressed by low water temperatures $\left(<15^{\circ} \mathrm{C}\right)$ (Yanagida et al. 2006). In gilthead sea bream farms, the minimum temperature for developing enteromyxosis varies from $18^{\circ} \mathrm{C}$ (Le Breton \& Marques 1995) to $22^{\circ} \mathrm{C}$ (Rigos et al. 1999), and outbreaks in French farms have only been observed when water temperature is $>20^{\circ} \mathrm{C}$ (Fleurance et al. 2008). The present study also confirms the inhibitory effect of low water temperatures on the development of enteromyxosis in gilthead sea bream, as no fish was infected in AT-2-L during the first $60 \mathrm{~d}$ p.i. in which water temperature reached a maximum of only $13.9^{\circ} \mathrm{C}$. However, when water temperature naturally increased up to $26^{\circ} \mathrm{C}$ at $216 \mathrm{~d}$ p.i. (mean water 

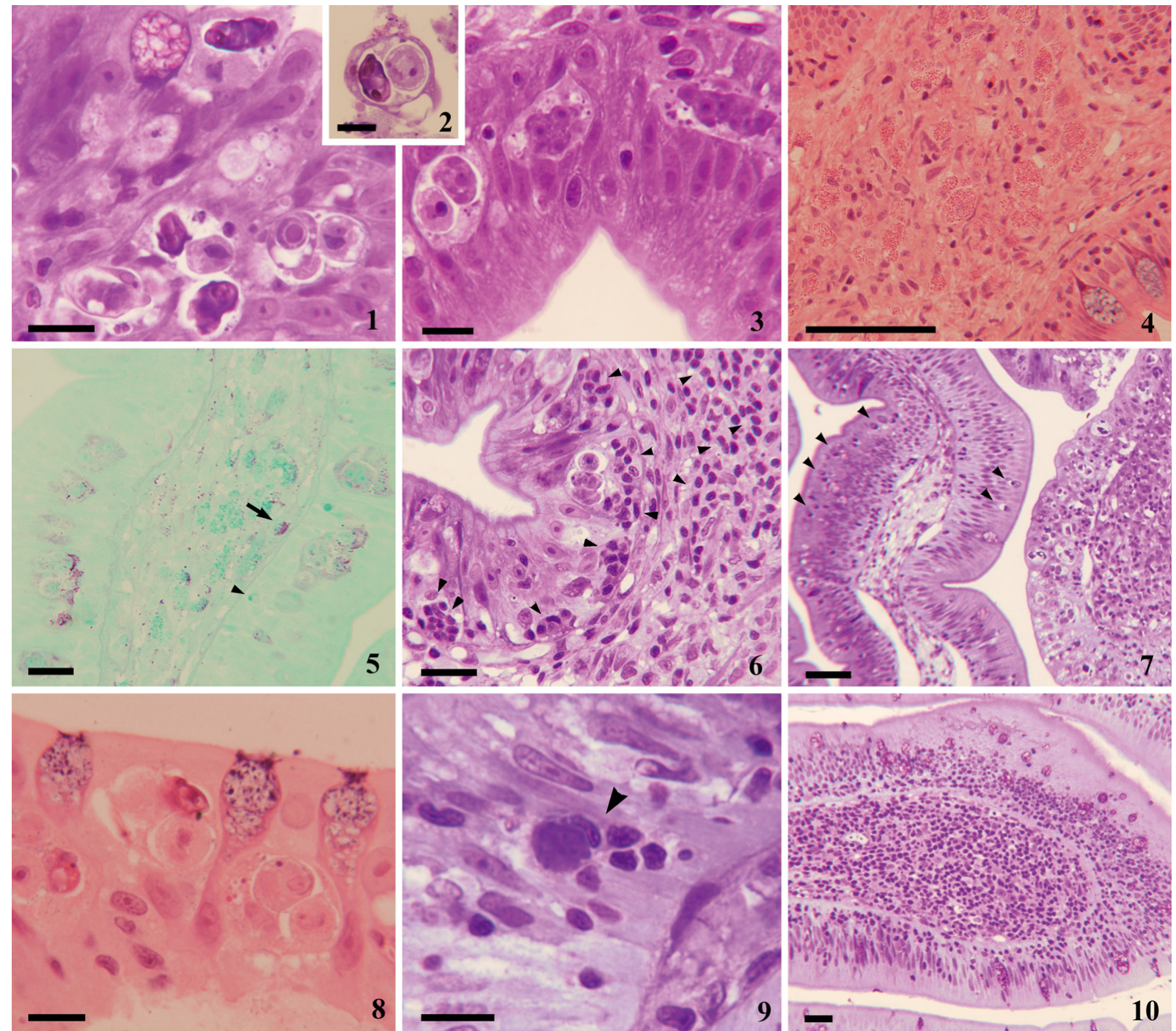

Figs. 1 to 10. Sparus aurata. Histological sections of intestines after experimental infections with Enteromyxum leei at $60 \mathrm{~d}$ post inoculation. Figs. 1 to 8. Anal transmission (AT-1). Fig. 1. Spores and sporogonic stages invading the epithelium of the posterior intestine (PI). Notice a mature spore about to be detached to the lumen. Scale bar $=10 \mu \mathrm{m}$. Fig. 2. Detail of a primary cell containing a mature spore and an accompanying cell released to the lumen of the PI, with remnants of epithelial cells. Scale bar $=$ $10 \mu \mathrm{m}$. Fig. 3. Proliferative stages in the epithelium of the middle intestine (MI). Scale bar $=10 \mu \mathrm{m}$. Fig. 4. Massive proliferation of eosinophilic granule cells (EGC1) in the hypertrophied lamina propria-submucosae of the MI. Scale bar $=20 \mu \mathrm{m}$. Fig. 5 . EGC2 in the lamina propria-submucosae, showing periodic acid-Schiff (PAS)-positive granules (arrow) that usually have a polarised pattern, and EGC1 with PAS-negative granules in the epithelium (arrowhead) of the MI. Notice the PAS-positivity of E. leei stages. Scale bar $=20 \mu \mathrm{m}$. Fig. 6. Lymphocytic infiltration (arrowheads) in the epithelium and lamina propria-submucosae of the MI. Scale bar $=20 \mu \mathrm{m}$. Fig. 7 . Panoramic view of an infected anterior intestine (AI) with a patchy distribution of the parasite (right side). Notice the abundance of rodlet cells (arrowheads) in the non-infected part (left side). Scale bar $=50 \mu \mathrm{m}$. Fig. 8. Goblet cells flanking parasitic stages in the epithelium of the AI. Scale bar $=10 \mu \mathrm{m}$. Figs. $9 \& 10$. Oral transmission (OT-1). Fig. 9. Residual parasite stages engulfed by a macrophage (arrowhead). Scale bar $=10 \mu \mathrm{m}$. Fig. 10. Massive proliferation of lymphocytes at the base of the epithelium and lamina propria-submucosa of the MI. Scale bar $=20 \mu \mathrm{m}$. Sections are stained with toluidine blue

(Figs. 1, 2, 6, 7, 9, 10), H\&E (Figs. 4 \& 8) or PAS (Fig. 5)

temperature between 60 and $216 \mathrm{~d}$ was $17.1^{\circ} \mathrm{C}$ ), the infection appeared. As in the tiger puffer, this re-emergence of $E$. leei in gilthead sea bream with increase in water temperature indicates the capability of this parasite to become latent during the cooler period. Water temperature greatly affects the initiation and progression of myxozoan infections. For some myxozoans, favorable water temperatures have been defined (Hedrick et al. 1993), but arrested development or latency in the host at low water temperatures has 
scarcely been documented for fish parasites (Olson 1981, Beaman et al. 1999). Furthermore, the only available report of arrested development for a Myxosporea during the pre-spore stage was not attributed to temperature (Higgins et al. 1993). This has important epidemiological consequences, since fish can pass as false negatives in epidemiological surveys during wintertime and become reservoirs and/or a source of the parasite to naïve fish when temperature rises in spring and summer. Further studies are needed to determine the parasite stages and the host sites where latency occurs at low temperatures.

Regardless of the temperature, all surviving R AT-2 fish were free of the parasite when sampled $326 \mathrm{~d}$ p.i., even though infection was clearly established in previous samplings. This recovery from infection has already been described for enteromyxosis (Yanagida et al. 2006) and other myxosporoses such as PKD (Morris et al. 2005).

Clear differences in the prevalence, intensity of infection and parasite stages were observed among the 3 parts of the digestive tract. The posterior intestine seems to be the first target site for Enteromyxum leei in gilthead sea bream, followed by the anterior portion. These differential preferences have also been observed in other infection routes, such as effluent (Estensoro et al. 2010), cohabitation and even oral routes (Cuadrado 2009). Similarly, in natural infections, a higher prevalence of infection was found in the rectum than in the proximal intestine in asymptomatic fish (Fleurance et al. 2008). Therefore, the higher infection levels found in the distal part of the intestine are not due to the peranal infection mode. However, in other Enteromyxum spp. oral and cohabitation trials, an anterior-posterior gradient was demonstrated (Redondo et al. 2004, Yanagida et al. 2006, Alvarez-Pellitero et al. 2008). In AT-1, the stomach remained free of parasites, whereas pyloric caeca were infected, as observed by other authors in advanced E. leei infections (Fleurance et al. 2008). This observation could indicate that the pyloric caeca might be invaded later on by the parasite, and that we could therefore consider the infection in AT-1 infected fish to be quite advanced in just $60 \mathrm{~d}$.

The histopathological damage caused by the parasite and the inflammatory host reaction were very similar to those described by other authors for different Enteromyxum leei-infected hosts (Diamant et al. 2006, Alvarez-Pellitero et al. 2008, Fleurance et al. 2008). The disruption of the integrity of the mucosa, desquamation and detachment of the epithelium, which correspond to advanced, chronic infections, was observed earlier than in cohabitation and effluent transmission trials. The apparent decrease in goblet and rodlet cells has also been reported in turbot Psetta maxima with severe E. scophthalmi infections (Bermúdez et al. 2010).
In the current study, peroral transmission failed. The histopathological study showed a cellular activation at the gut level in $\mathrm{R}$ fish, and the observed cell debris could correspond to abortive stages that were engulfed by macrophages and were not capable of proliferating in the tissue. In previous studies, oral transmission of Enteromyxum leei to gilthead sea bream produced very variable results ranging from 0 to $86.7 \%$ prevalence of infection (Diamant 1997, Sitjà-Bobadilla et al. 2007). E. leei was also orally transmitted to red sea bream Pagrus major, the tiger puffer (Yasuda et al. 2002, Yanagida et al. 2004) and several fresh water species (Diamant et al. 2006). Similarly, a high prevalence of infection by E. scophthalmi was obtained orally for turbot (100\%, 22 d p.i.) (Redondo et al. 2004). The existence of refractive or nonsusceptible gilthead sea bream strains (Sitjà-Bobadilla et al. 2007) cannot explain the failure of the oral route in the current study, as an identical group of fish was successfully infected using the same inoculum, dose and water temperature by the anal route. Differences in the presence or absence of a true stomach, acidic gastric $\mathrm{pH}$ and digestive enzyme activity have been hypothesized to explain the failure in the transmission of E. leei by the oral route in some species (Diamant et al. 2006).

In conclusion, this novel peranal transmission greatly improved the infection levels and the timing achieved by other routes and further confirms the direct transmission of Enteromyxum leei without the involvement of invertebrate hosts. This ease of transmission makes enteromyxosis an excellent model for the study of host-parasite interactions, but this fact and the described arrested development at low temperatures are also responsible for the spread of the disease under farming conditions, and greatly hamper its prevention and control.

Acknowledgements. This work was funded by the Spanish Ministerio de Educación y Ciencia (MEC) (AGL2006-13158C03-01) and Ministerio de Ciencia e Innovación (AGL200913282-C02-01). Additional funding was obtained from the 'Generalitat Valenciana' (research grant PROMETEO 2010/006). I.E. received a Spanish FPI-PhD fellowship from MEC. The authors thank R. del Pozo for excellent assistance in sampling and PCR diagnosis, and J. Montfort and L. Rodríguez for histological processing.

\section{LITERATURE CITED}

Alvarez-Pellitero P, Palenzuela O, Sitjà-Bobadilla A (2008) Histopathology and cellular response in Enteromyxum leei (Myxozoa) infections of Diplodus puntazzo (Teleostei). Parasitol Int 57:110-120

- Beaman HJ, Speare DJ, Brimacombe M (1999) Regulatory effects of water temperature on Loma salmonae (Microspora) development in rainbow trout. J Aquat Anim Health 11:237-245 
Bermúdez R, Losada AP, Vázquez S, Redondo MJ, AlvarezPellitero P, Quiroga MI (2010) Light and electron microscopic studies on turbot Psetta maxima infected with Enteromyxum scophthalmi: histopathology of turbot enteromyxosis. Dis Aquat Org 89:209-221

Crosbie PBB, Nowak BF (2004) Immune responses of barramundi, Lates calcarifer (Bloch), after administration of an experimental Vibrio harveyi bacterin by intraperitoneal injection, anal intubation and immersion. J Fish Dis 27: $623-632$

Cuadrado M (2009) Enteromixosi produïda per Enteromyxum leei (Diamant, Lom i Dyková 1994) en espàrids d'interès comercial del Mediterrani. PhD thesis, Autonomous University of Barcelona

Diamant A (1995) Myxidium leei (Myxosporea) infections in sharpsnout sea bream Diplodus puntazzo (Cetti) and common sea bream Pagrus pagrus (L.) (Sparidae). 4th Int Symp Fish Parasitology, Oct. 3-7, Munich. Program and Book of Abstracts, Abstract \#8

Diamant A (1997) Fish-to-fish transmission of a marine myxosporean. Dis Aquat Org 30:99-105

> Diamant A (1998) Red drum Sciaenops ocellatus (Sciaenidae), a recent introduction to Mediterranean mariculture, is susceptible to Myxidium leei (Myxosporea). Aquaculture 162: 33-39

Diamant A, Wajsbrot N (1997) Experimental transmission of Myxidium leei in gilthead sea bream Sparus aurata. Bull Eur Assoc Fish Pathol 17:99-103

> Diamant A, Lom J, Dyková I (1994) Myxidium leei n. sp., a pathogenic myxosporean of cultured sea bream Sparus aurata. Dis Aquat Org 20:137-141

> Diamant A, Ram S, Paperna I (2006) Experimental transmission of Enteromyxum leei to freshwater fish. Dis Aquat Org 72:171-178

Estensoro I, Benedito-Palos L, Palenzuela O, Kaushik S, SitjàBobadilla A, Pérez-Sánchez J (2010) The nutritional background of the host alters the disease course in a fishmyxosporean system. Vet Parasitol doi:10.1016/j.vetpar. 2010.09.015

Fleurance R, Sauvegrain C, Marques A, Le Breton A, Guereaud C, Cherel Y, Wyers M (2008) Histopathological changes caused by Enteromyxum leei infection in farmed sea bream Sparus aurata. Dis Aquat Org 79:219-228

Golomazou E, Athanassopoulou F, Karagouni E, Tsagozis P, Tsantilas H, Vagianou S (2006) Experimental transmission of Enteromyxum leei Diamant, Lom and Dyková, 1994 in sharpsnout sea bream, Diplodus puntazzo C. and the effect on some innate immune parameters. Aquaculture 260:44-53

Hedrick RP, McConnell E, de Kinkelin P (1993) Proliferative kidney disease of salmonid fish. Annu Rev Fish Dis 3: 277-290

Higgins MJ, Margolis L, Kent ML (1993) Arrested development in a freshwater myxosporean, Myxidium salvelini, following transfer of its host, the sockeye salmon (Oncorhynchus nerka), to sea water. J Parasitol 79: 403-407

Le Breton A, Marques A (1995) Occurrence of a histozoic Myxidium infection in two marine cultured species: Puntazzo puntazzo C. and Pagrus major. Bull Eur Assoc Fish Pathol 15:210-212

Marino F, Macri D, Paruta S, Busalacchi B, Genovese L, De Vico G (2004) Black spot seabream (Pagellus bogaraveo), a new susceptible host for Myxidium leei. Extended Abstracts and Short Communications Booklet, Aquaculture Europe, Barcelona. European Aquaculture Society Special Publication No. 34, p 524-525

Morris DJ, Ferguson HW, Adams A (2005) Severe, chronic proliferative kidney disease (PKD) induced in rainbow trout Oncorhynchus mykiss held at a constant $18^{\circ} \mathrm{C}$. Dis Aquat Org 66:221-226

> Muñoz P, Cuesta A, Athanassopoulou F, Golomazou E and others (2007) Sharpsnout sea bream (Diplodus puntazzo) humoral immune response against the parasite Enteromyxum leei (Myxozoa). Fish Shellfish Immunol 23: $636-645$

Olson RE (1981) Effects of low temperature on the development of the microsporidan Glugea stephani in English sole Parophrys vetulus. J Wildl Dis 17:559-562

Padrós F, Palenzuela O, Hispano C, Tosas O, Zarza C, Crespo S, Alvarez-Pellitero P (2001) Myxidium leei (Myxozoa) infections in aquarium-reared Mediterranean fish species. Dis Aquat Org 47:57-62

> Palenzuela O (2006) Myxozoan infections in Mediterranean mariculture. Parassitologia 48:27-29

Palenzuela O, Bartholomew JL (2002) Molecular tools for the diagnosis of Ceratomyxa shasta (Myxozoa). In: Cunningham CO (ed) Molecular diagnosis of salmonid diseases. Kluwer Academic Publishers, Dordrecht, p 285-98

Paperna I (1998) Mariculture versus environment: risks and impacts. Biol Mar Mediterr 5:381-389

Redondo MJ, Palenzuela O, Alvarez-Pellitero P (2004) Studies on transmission and life cycle of Enteromyxum scophthalmi (Myxozoa), an enteric parasite of turbot Scophthalmus maximus. Folia Parasitol 51:188-198

Rigos G, Katharios P (2010) Pathological obstacles of newlyintroduced fish species in Mediterranean mariculture: a review. Rev Fish Biol Fish 20:47-70

> Rigos G, Christophilogiannis P, Yiagnisi M, Andriopoulou A, Koutsodimou M, Nengas I, Alexis M (1999) Myxosporean infection in Greek mariculture. Aquacult Int 7:361-364

Sakiti PN, Tarer V, Jacquemin D, Marques A (1996) Présence en Méditerranée occidentale d'une Myxosporidie histozoïque pathogène dans les élevages de daurade, Sparus aurata L. Ann Sci Nat B 17:123-127

Shaw RW, Kent ML, Adamson ML (1998) Modes of transmission of Loma salmonae (Microsporidia). Dis Aquat Org 33:151-156

Sitjà-Bobadilla A, Diamant A, Palenzuela O, Alvarez-Pellitero P (2007) Effect of host factors and experimental conditions on the horizontal transmission of Enteromyxum leei (Myxozoa) to gilthead sea bream, Sparus aurata L., and European sea bass, Dicentrarchus labrax (L.). J Fish Dis 30:243-250

Swan CM, Lindstrom NM, Cain KD (2008) Identification of a localized mucosal immune response in rainbow trout, Oncorhynchus mykiss (Walbaum), following immunization with a protein-hapten antigen. J Fish Dis 31:383-393

> Vervarcke S, Ollevier F, Kinget R, Michoel A (2005) Mucosal response in African catfish after administration of Vibrio anguillarum $\mathrm{O} 2$ antigens via different routes. Fish Shellfish Immunol 18:125-133

Yanagida T, Nomura Y, Kimura T, Fukuda Y, Yokoyama $H_{\text {, }}$ Ogawa K (2004) Molecular and morphological redescriptions of enteric Myxozoans, Enteromyxum leei (formerly Myxidium sp. TP) and Enteromyxum fugu comb. n. (syn. Myxidium fugu) from cultured tiger puffer. Fish Pathol 39:137-143

Yanagida T, Sameshima M, Nasu H, Yokoyama H, Ogawa K (2006) Temperature effects on the development of Enteromyxum spp. (Myxozoa) in experimentally infected tiger puffer, Takifugu rubripes (Temminck \& Schlegel). J Fish Dis 29:561-567

Yasuda H, Ooyama T, Iwata K, Tun T, Yokoyama H, Ogawa K 
(2002) Fish-to-fish transmission of Myxidium spp. (Myxozoa) in cultured tiger puffer suffering emaciation disease. Fish Pathol 37:29-33

Yasuda H, Ooyama T, Nakamura A, Iwata K, Palenzuela O, Yokoyama H (2005) Occurrence of the myxosporean emaciation disease caused by Enteromyxum leei in cultured

Editorial responsibility: Dieter Steinhagen,

Hannover, Germany
Japanese flounder Paralichthys olivaceus. Fish Pathol 40:175-180

Zrnčić S, Oraić D, Šoštarić B, Fillić I (1998) First occurrence of Myxidium leei in cultivated sharp snouted Sparus (Puntazzo puntazzo) in Croatia. 3rd Int Symp Aquat Animal Health. Baltimore, MD

Submitted: May 12, 2010; Accepted: July 9, 2010

Proofs received from author(s): September 7, 2010 